\title{
Screening of Obese Offspring of First-Cousin Consanguineous Subjects for the Angiotensin-Converting Enzyme Gene with a 287-bp Alu Sequence
}

\author{
Amal F Alshammary, Imran Ali Khan* \\ Department of Clinical Laboratory Sciences, College of Applied Medical Sciences, King Saud University, Riyadh, Saudi Arabia
}

Background: Consanguinity, defined as a blood relation between couples, is associated with genetic diseases in their offspring. In Saudi Arabia, obesity is considered a major health problem associated with increased risks of cardiovascular disease, insulin resistance, and type 2 diabetes mellitus. Angiotensin-converting enzyme (ACE) with insertion (I) and deletion (D) polymorphisms of an Alu-287 bp sequence has been implicated in multiple metabolic disorders, including obesity. To date, no studies have been conducted in the Saudi population regarding the $A C E$ gene in consanguineous offspring with obesity. Therefore, the present study aimed to investigate genetic associations in offspring of first cousins, and specifically the relationship between obesity and ACE (Alu$287 \mathrm{bp}$ ) was evaluated in the Saudi population.

Methods: In total, 91 cases of obesity in the offspring of first-cousin couples and 100 control subjects without obesity but with a family history of consanguinity were included. Using genomic DNA, ACE ID polymorphisms between the cases and controls were evaluated by polymerase chain reaction.

Results: There were strong differences in the height, weight, and body mass index between the cases and controls $(P<0.001)$. A genotype analysis confirmed the strong association with allele frequencies $(P<0.001$; odds ratio, 4.902; 95\% confidence interval, 2.867-8.379) when compared between the cases and controls. One-way analysis of variance showed a positive correlation with height and logistic regression (covariance) that could not be strongly correlated $(P>0.05)$.

Conclusion: In conclusion, the ACE gene polymorphism was found, through allele frequencies, to be associated with obesity in the offspring of consanguineous first cousins in the Saudi population.

Key words: Consanguinity, Obesity, Offspring, First cousin, Consanguineous couples, Angiotensin-converting enzyme-insertion/deletion, Alu-287 bp

\author{
Received August 11, 2020 \\ Reviewed October 19, 2020 \\ Accepted January 26, 2021 \\ *Corresponding author \\ Imran Ali Khan \\ (iD) \\ https://orcid.org/0000-0002-9746-5300 \\ Department of Clinical Laboratory \\ Sciences, College of Applied Medical \\ Sciences, King Saud University, \\ Riyadh 11433, Saudi Arabia \\ Tel: +966-501112806 \\ Fax: +966-114693851 \\ E-mail:imkhan@ksu.edu.sa
}

\section{INTRODUCTION}

Clinical genetics defines consanguineous marriages as the union between blood-related couples, e.g., first cousins, double first cousins, second cousins, or even more closely related individuals, leading to a coefficient of inbreeding $(\mathrm{F})$ in their progeny of $>0.01$. $^{1}$ Consanguineous marriages, also termed consanguineous unions, refer to weddings between two individuals with at least one trace- able common ancestor, and their offspring are considered offspring of consanguineous couples. ${ }^{2}$ First cousins are the most frequent cases; accounting for $10.4 \%$ of consanguineous couples worldwide. ${ }^{3}$ In medical genetics, the effects of consanguinity and inbreeding on human health are major focuses of research. ${ }^{4}$ Consanguineous marriages account for $\sim 20 \%$ of marriages worldwide (i.e., $\sim 1.2$ billion), but that prevalence varies according to ethnicity, religion, and culture, with rates of $0.5 \%$ in Europe, $0.2 \%$ in the United States, and 
$67.6 \%$ in the Middle East. ${ }^{5}$ In the offspring of consanguineous couples, autozygosity mapping is used to identify causal mutations in autosomal recessive disorders. ${ }^{6}$ These analyses have indicated that children of first consanguineous cousins have an elevated risk for genetic disorders and congenital anomalies compared with children in the normal population. ${ }^{7}$ Recessive genes do not result in the expression of genetic diseases owing to low visibility relative to dominant genes. However, the inheritance of two identical copies of similar sporadic recessive gene variants results in the expression of genetic diseases. ${ }^{8}$

Genome-wide association studies, meta-analyses, single nucleotide polymorphisms, exome sequencing, next-generation sequencing, and cohort studies have identified multiple variants in complex and multifactorial human diseases. Angiotensin-converting enzyme ( $A C E$; Online Mendelian Inheritance in Man [OMIM]: 106180) has been studied in many human diseases. ${ }^{9}$ The relationship between obesity and the insertion (I) and deletion (D) polymorphisms in the ACE gene is expressed in adipose tissues. ${ }^{10}$ The leptin melanocortin pathway is related to the association between consanguinity and obesity (OMIM: 601665), ${ }^{11}$ a multifactorial disease characterized by excess body fat, a reduced life expectancy, and increased health complications. ${ }^{12}$ Obesity is becoming a global epidemic among the heritable human traits. ${ }^{13}$ Body mass index (BMI) is a commonly used quantitative measure of adiposity. According to the International Obesity Task Force, overweight is defined as a BMI exceeding the 85 th percentile, and obesity refers to a BMI exceeding the 95th percentile. ${ }^{14}$ In Saudi Arabia, childhood and adulthood obesity have become major health concerns, with incidences of $44 \%$ in females and $28 \%$ in males. ${ }^{15}$ Kasim et al. ${ }^{16}$ concluded that genetic polymorphisms are associated with overweight and obese conditions. The renin angiotensin system (RAS) also contributes to the pathophysiology of obesity. ${ }^{17}$ Initial studies in the 1990 s by Rigat et al. ${ }^{18}$ confirmed that a 287-bp insertion (an Alu repetitive sequence) in $A C E$ is strongly associated with circulatory enzyme levels. Subjects with the DD genotype, where D indicates a deletion, had ACE plasma levels that were about twice the levels in subjects with a different genotype. ${ }^{18}$ Accordingly, the ACE (I) and (D) polymorphisms are associated with plasma $A C E$ levels. The ACE gene has been mapped to chromosome 17q23; it is $21 \mathrm{~kb}$ and includes 26 exons and 25 introns. ${ }^{19} A C E$ is the first genetic variant as- sociated with human physical performance with a strong linkage disequilibrium with other genetic factors. $A C E$ plays a major role in the RAS cascade through the conversion of angiotensin I to angiotensin II. ${ }^{20}$ However, limited genetic studies of consanguinity, obesity, and genetic polymorphism have focused on the Saudi Arabia population. In this study, $A C E$ gene polymorphisms were evaluated owing to their importance in a wide range of human diseases. The aim of the current study was to investigate $A C E$ polymorphisms in offspring of first cousins with obesity in the Saudi population.

\section{METHODS}

\section{Recruitment of clinical and non-clinical samples}

This case-control study was performed at the College of Applied Medical Sciences (CAMS), King Saud University (KSU), in the capital city of Saudi Arabia. The study protocol was approved by the Ethics Committee of CAMS-KSU, with the approval number 01/1435-1436, and signed informed consent was obtained from all participants. The STROBE statement (guidelines for reporting observational studies in epidemiology, accessible via the EQUATOR network and used to improve the consistency and transparency of health research) was implemented throughout the design, review, interpretation, planning, and revisions of the study. In total, 91 saliva samples from the obese offspring of first cousins were collected from various locations in Riyadh, such as the Sahara Mall, Saudi boys' school, King Khalid University Hospitals, and KSU Medical College. Blood samples from 100 control subjects were obtained from the KSU premises. The inclusion criterion for the cases was offspring of first cousins with obesity, as defined by the World Health Organization. ${ }^{21}$ The exclusion criteria were non-obese first cousin offspring, first cousin siblings, non-offspring of first cousins, and offspring of second cousins. Controls were mainly non-obese subjects $\left(\mathrm{BMI}<25 \mathrm{~kg} / \mathrm{m}^{2}\right)$ without any metabolic, renal, or complex disorders, and whose parents did not belong to a similar family pedigree, i.e., parents were not involved in any degree of consanguineous marriages.

\section{Nucleotide analysis}

Using ethylenediaminetetraacetic acid (EDTA) vacutainers, $2 \mathrm{~mL}$ of whole blood leukocytes was collected from all control subjects. 
For the cases, 1-2 mL samples of saliva were collected using Oragene DNA Collection Tubes (Norgen Biotek, Thorold, ON, Canada). The saliva tubes were stored at room temperature. The PrepIT-L2P Kit (Norgen Biotek) was used to extract genomic DNA from the saliva, and the Norgen DNA Extraction Kit was used for extraction from blood. EDTA samples were separated as per the protocol provided by the company. Then, $100 \mu \mathrm{L}$ of Tris EDTA buffer was added to each sample, and the NanoDrop was used to evaluate DNA purity at 260/280 nm (NanoDrop 2000 Spectrophotometer; Thermo Scientific, Waltham, MA, USA). ACE (rs4646994) genotyping was performed using primers. ${ }^{20}$ Thermal polymerase chain reaction (PCR) was performed using the specific primers. The oligonucleotide sequences were designed to flank the targeted region of the genome at intron 16 of ACE. PCR was performed using $25-\mu \mathrm{L}$ reaction volumes and the following conditions: $95^{\circ} \mathrm{C}$ for 5 minutes; 35 cycles of $95^{\circ} \mathrm{C}$ for 30 seconds, $60^{\circ} \mathrm{C}$ for 30 seconds, and $72^{\circ} \mathrm{C}$ for 45 seconds; and a final extension at $72^{\circ} \mathrm{C}$ for 5 minutes. Ethidium bromide-stained 3\% agarose gel electrophoresis was used to evaluate the insertion (490 bp with 287-bp Alu insertion) and deletion (190 bp) status of undigested PCR products. The ID base pairs were considered heterozygous with the appearance of insertion and deletion of 287 Alu base pair sequences (Fig. 1). The agarose gel was evaluated by ultraviolet gel documentation. Molecular analysis was performed in the male campus of the Clinical Laboratory Sciences Department in CAMS at KSU (Lab No. G-141).

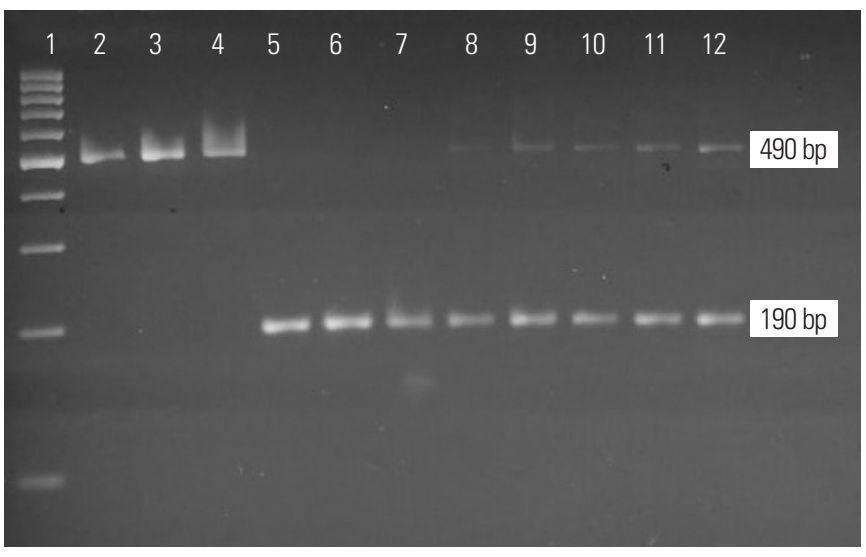

Figure 1. Presentation of $3 \%$ agarose gel electrophoresis with undigested angiotensin-converting enzyme (ACE) products. Lane 1: 100 bp ladder, lane 2-4: II genotype (490 bp), lane 5-7: DD genotype (190 bp), lane 8-12: ID genotype (490/190 bp). I, insertion; $\mathrm{D}$, deletion.

\section{Statistical analysis}

Clinical data are presented as mean \pm standard deviation. Pearson chi-square experiments evaluated the Hardy-Weinberg Equilibrium (HWE) for ACE. Genotype and allele frequencies were determined from Fisher's exact tests with odds ratios (ORs), 95\% confidence intervals (CIs), and $P$-values. One-way analysis of variance (ANOVA) and multinomial logistic regression using IBM SPSS version 25.0 (IBM Corp., Armonk, NY, USA) was performed. From an R program, scatter plots and box plots were generated (Figs. 2, 3 and Supplementary Figs. 1, 2). All statistical studies were carried out using various software applications, including SPSS, OpenEpi, and R. A $P$-value of $<0.05$ indicated statistical relevance.

\section{RESULTS}

\section{Descriptive analysis}

The anthropometric characteristics of the cases and controls are documented in Table 1. Obesity cases (mean age, 29.4 \pm 12.45 years)

\section{A}
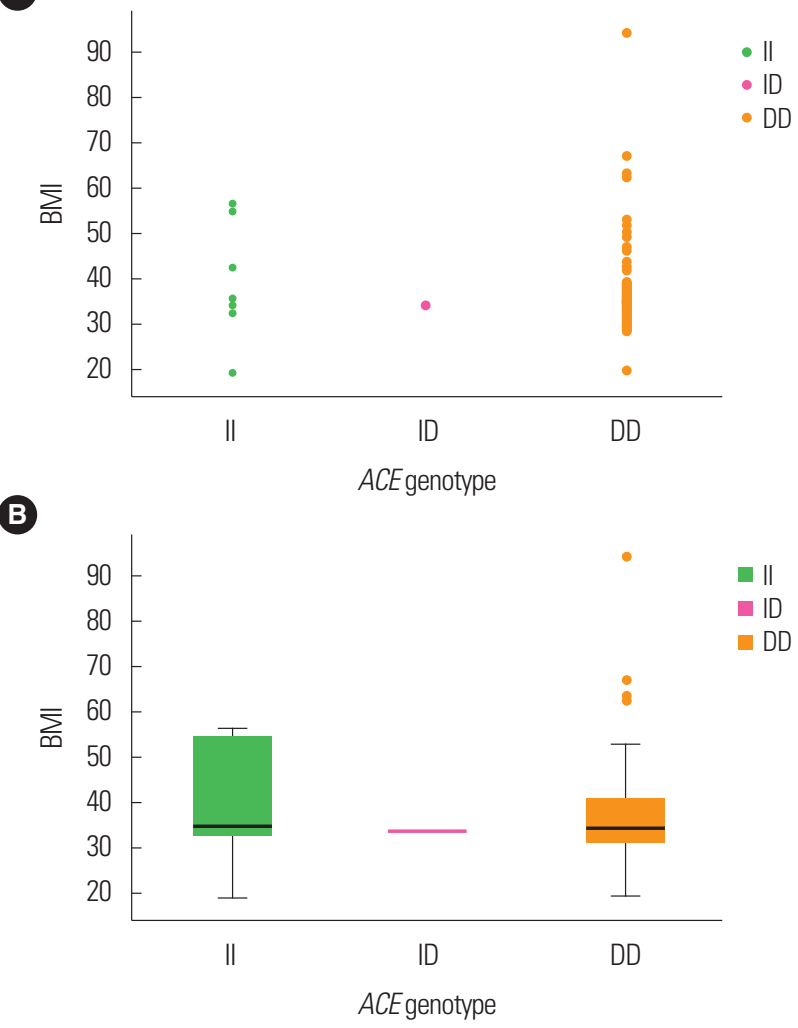

Figure 2. Scatter plot $(A)$ and box plot $(B)$ representing the association between angiotensin-converting enzyme (ACE) genotypes and body mass index (BMI) in obesity cases. I, insertion; D, deletion. 
were younger than the controls (mean age, $48.05 \pm 10.69$ years), and sex ratio differed between groups. Obese offspring showed significantly higher values for anthropometric parameters, such as weight and BMI, than those of the controls $(P<0.001)$. The average height of the cases was found to be $156.28 \mathrm{~cm}$, whereas $163.68 \mathrm{~cm}$ was the average height among controls, which indicates that the control

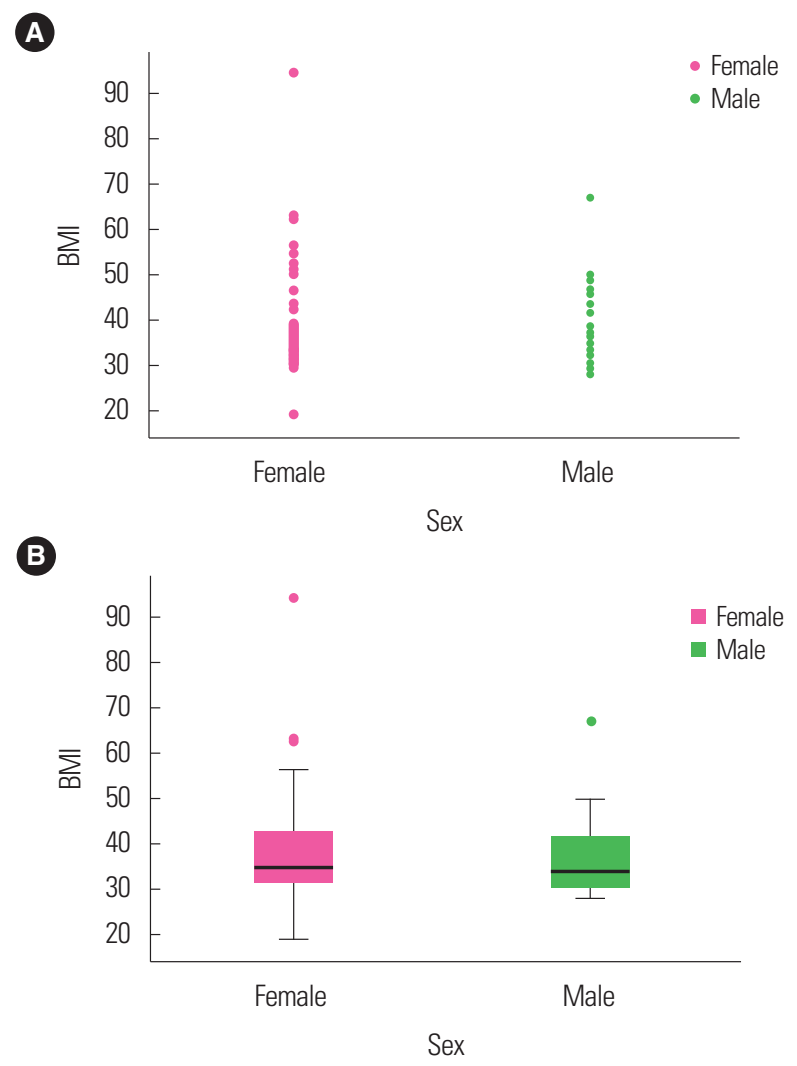

Figure 3. Representation of the association between sex and body mass index (BMI) of obesity cases through scatter plot (A) and box plot (B). subjects were prone to be taller than the case subjects. However, although the sex differences between the cases and controls were statistically significant $(P=0.001)$, the differences in age $(P=0.13)$ and height $(P=0.16)$ were not.

\section{HWE analysis}

Genotype frequencies for $A C E$ in the control subjects were in $\operatorname{HWE}(P=0.028)$, and the estimation of power and sample size was found to be $80 \%$ in this study (Supplementary Table 1).

\section{$A C E$ genotyping analysis}

Genotype and allele frequencies for the ACE Alu sequence polymorphism for both cases and controls are shown in Table 2. The II and ID genotypes were detected at lower frequencies and the DD genotype was detected at a higher frequency among the cases (Fig. 2) than among the controls (Supplementary Fig. 1) (II: 11\% vs. 10\%, ID: $1.1 \%$ vs. $58 \%$, and DD: $87.9 \%$ vs. $32 \%)$. The OR for ID vs. II

Table 1. Anthropometric details of first cousin siblings and control subjects

\begin{tabular}{lccc}
\hline Variable & Case $(\mathrm{n}=91)$ & Control $(\mathrm{n}=100)$ & $P$ \\
\hline Age $(\mathrm{yr})$ & $29.40 \pm 12.45$ & $48.05 \pm 10.69$ & 0.130 \\
Sex $($ male:female) & 38.53 & $62: 38$ & $0.001^{*}$ \\
Weight $(\mathrm{kg})$ & $98.19 \pm 31.58$ & $67.23 \pm 11.48$ & $<0.001^{*}$ \\
Height $(\mathrm{cm})$ & $156.28 \pm 20.31$ & $163.68 \pm 8.84$ & 0.160 \\
BMl $\left(\mathrm{kg} / \mathrm{m}^{2}\right)$ & $38.10 \pm 11.07$ & $24.83 \pm 3.52$ & $<0.001^{*}$ \\
First cousin siblings & $91(100)$ & 0 & $<0.001^{*}$ \\
\hline
\end{tabular}

Values are presented as mean \pm standard error or number (\%).

* $P$-values were calculated between the cases and control subjects and indicated a significant association when the values were $<0.05$.

$\mathrm{BMl}$, body mass index.

Table 2. Genotype and allele frequency distributions of the ACE polymorphism in the obese offspring of first cousins (cases) and controls

\begin{tabular}{lcccccc}
\hline Genotype/allele & Case $(\mathrm{n}=91)$ & Control $(\mathrm{n}=100)$ & $\mathrm{OR}(95 \% \mathrm{Cl})$ & $P$ & $\mathrm{OR}(95 \% \mathrm{Cl})^{*}$ & $P^{\dagger}$ \\
\hline$\|$ & $10(11.0)$ & $10(10)$ & Reference & Reference & Reference & Reference \\
ID & $1(1.1)$ & $58(58)$ & $0.017(0.002-0.149)$ & $<0.001$ & $0.019(0.002-0.148)$ & $<0.001$ \\
DD & $80(87.9)$ & $32(32)$ & $2.500(0.095-6.579)$ & 0.058 & $2.200(0.099-6.582)$ & 0.036 \\
Dominant (II vs. ID+DD) & $10(11)$ & $10(10)$ & $1.110(0.440-2.806)$ & 0.820 & $1.130(0.480-2.824)$ & 0.680 \\
Co-dominant (ID vs. II+ID) & $1(1.1)$ & $58(58)$ & $0.008(0.001-0.060)$ & $<0.001$ & $0.009(0.002-0.090)$ & $<0.001$ \\
Recessive (II+ID vs. DD) & $11(12.1)$ & $68(68)$ & $0.064(0.030-0.130)$ & $<0.001$ & $0.066(0.032-0.140)$ & $<0.001$ \\
I allele & $21 \pm 12$ & $78 \pm 39$ & Reference & Reference & Reference & Reference \\
D allele & $161 \pm 89$ & $122 \pm 61$ & $4.902(2.867-8.379)$ & $<0.001$ & $4.905(2.871-8.382)$ & $<0.001$ \\
\hline
\end{tabular}

Values are presented as number (\%) or mean \pm standard error. Reference indicates the II genotypes and I allele.

${ }^{*}$ The correlation between age/sex and the genotypes; ${ }^{\dagger}$ - -values were calculated between the cases and control subjects and indicated a significant association when values were $<0.05$.

$A C E$, angiotensin-converting enzyme; $\mathrm{OR}$, odds ratio; $\mathrm{Cl}$, confidence interval; I, insertion; $\mathrm{D}$, deletion. 
was 0.017 (95\% CI, 0.002-0.14; $P<0.001)$ and for DD vs. II was 2.5 (95\% CI, 0.095-6.579; $P=0.058$ ). A negative association was confirmed when comparing the dominant (IIvs. ID+DD: OR, 1.11; 95\% CI, $0.44-2.806 ; P=0.82)$ with the recessive modes of inheritances (DD vs. II+ID: OR, 15.45; 95\% CI, 7.24-32.96; $P<0.001$ ), as well as with the co-dominant mode (ID vs. II+DD: OR, 0.008; 95\% CI, 0.001-0.06; $P<0.001)$. The allele frequencies for D and I in cases of offspring obesity were $88.5 \%$ and $11.5 \%$, respectively, whereas in the control subjects, the frequencies were $61 \%$ and $39 \%$, respectively; a significant association was detected (OR, 4.902; 95\% CI, 2.867-8.379; $P<0.001)$. After age and sex were adjusted, both the recessive model (OR, 0.064; 95\% CI, 0.03-0.13; $P<0.001)$ and the dominant allele (OR, 1.11; 95\% CI, 0.44-2.806; $P=0.82)$ were strongly associated.

\section{ANOVA analysis}

One-way ANOVA with genotypes II, ID, and DD and anthropometric measurements such as age $(P=0.47)$, weight $(P=0.74)$, height $(P=0.01)$, and BMI $(P=0.85)$ were performed. The current findings of the analysis showed that height was positively correlated with the three different genotypes, and the ID genotypes were found to be elevated to $168.00 \pm 0.00 \mathrm{~cm}$ and accompanied by $158.28 \pm$ $16.61 \mathrm{~cm} \mathrm{DD}$ genotypes and then by $139.17 \pm 36.40 \mathrm{~cm}(P=0.01)$ II genotypes (Supplementary Table 2).

\section{Multinomial logistic regression analysis}

Considering the $A C E$ II genotype as the reference group documented in Table 3, the association of genotype frequencies with different demographic and clinical covariates of studied polymor-

Table 3. Multinomial logistic regression analysis

\begin{tabular}{lcc}
\hline Characteristics & \multicolumn{1}{c}{ OR $(95 \% \mathrm{CI})$} & $P$ \\
\hline Age $(\mathrm{yr})$ & $0.692(0.547-0.874)$ & 0.002 \\
Sex (male:female) & $0.008(0.000-11.587)$ & 0.193 \\
Weight $(\mathrm{kg})$ & $1.073(0.929-1.238)$ & 0.338 \\
Height $(\mathrm{cm})$ & $0.966(0.817-1.142)$ & 0.684 \\
BMI $\left(\mathrm{kg} / \mathrm{m}^{2}\right)$ & $1.860(1.081-3.201)$ & 0.025 \\
ACE $\|$ & 1 (Reference) & 0.329 \\
ACE ID & $0.001(0.001-93,776.679)$ & 0.303 \\
ACE DD & $8.415(0.269-263.133)$ & 0.225 \\
\hline
\end{tabular}

Cox \& Snell $R^{2}: 0.707$.

$\mathrm{OR}$, odds ratio; $\mathrm{Cl}$, confidence interval; $\mathrm{BMl}$, body mass index; $A C E$, angiotensin-converting enzyme; I, insertion; $\mathrm{D}$, deletion. phisms such as age, sex, weight, height, and BMI with ACE II, ID, and DD genotypes was also evaluated. A positive correlation $(P<$ 0.05) was not demonstrated in the sample population for any of the covariates. No statistical correlation was shown in cases with either the ID genotype (OR, 0.001; 95\% CI, 0.001-93,776.679; $P=0.303$ ) or the DD genotype (OR, 8.415; 95\% CI, 0.269-263.133; $P=0.225$ ). The Cox and Snell $\mathrm{R}^{2}$ was found to be 0.707 .

\section{Association between $A C E$ genotypes and BMI for cases and control subjects}

The ACE genotypes are expressed in Fig. 2B and Supplementary Fig. 1 in relation to BMI among cases and controls. Among the cases, as compared to the II and ID genotypes, BMI was found to be elevated in the DD genotypes, while among the controls, BMI was highest in the DD and ID genotypes followed by the II genotypes. Fig. 3 demonstrates the correlation of BMI using the scatter plot (Fig. 3A) and box plot (Fig. 3B) in sex-wise parameters. In comparison with males among the obesity cases, the BMI was found to be higher in females, whereas among the controls, both females and males were documented to have similar BMI, though it was somewhat higher in males (Supplementary Fig. 2).

\section{DISCUSSION}

This case-control study of 91 cases and 100 controls provides the first analysis of the ACE gene ID polymorphism in the offspring of first-cousin consanguineous partners in the Saudi population. Our results confirm a stronger positive association with alleles $(P<0.001)$ in the cases compared with the controls. However, the ID frequency was higher in controls than in cases. The dominant, recessive, and co-dominant modes of inheritances all yielded non-significant associations $(P>0.05)$. The definition of BMI was derived from the Quetelet or Kaup index and was developed by the World Health Organization for the evaluation of any adult individual as the weight $(\mathrm{kg})$ divided by the height squared $\left(\mathrm{m}^{2}\right)$. In the Saudi population, BMI plays a very important role in school children aged 2-19 years. ${ }^{22}$ An earlier study in Saudi Arabia has documented that one of four adult males and one of three adult females are classified as obese. In general, obesity is associated with non-communicable diseases such as type 2 diabetes mellitus (T2DM), hypertension (HTN), ob- 
structive sleep apnea, hyperlipidemia, and osteoarthritis. ${ }^{23}$ The difference between the obesity and overweight statuses is not substantial; both are strongly associated with mental health, eating disorders, and nutritional problems, especially in Saudi Arabia. ${ }^{24}$ Multiple studies of the Saudi population have evaluated obesity in various sectors, including clinical, hospital-based, case-control, epidemiological, nutritional, genetic, and region-wide studies, and none has documented the precise cause of obesity in children and adult males and females. In the present study, offspring of first-cousin consanguineous couples with high BMIs (obesity) were evaluated. This is the first genetic case-control study in the Saudi population to consider subjects with obesity from consanguineous marriages.

The relationship between consanguinity and genetic disorders is now recognized, and it is predicted that one billion people worldwide from different cultural communities are in consanguineous marriages, particularly in the Middle East, Asia, and North Africa, where these marriages represent $20 \%-50 \%$ of total marriages. In Saudi Arabia, a nearly 50\% rate of consanguinity has been reported, with rates as high as $80 \%$ in some specific regions; marriages between first cousins are particularly frequent, ranging between $28 \%$ and $40 \%{ }^{25}$ The risks associated with consanguinity for first-cousin parents have been confirmed by analyses of birth defects in newborns. ${ }^{26}$ These risks are passed to offspring through autosomal recessive gene mutations inherited from a common ancestor. ${ }^{27}$ Loss of function (missense) variants are expected to disrupt the functions of protein-coding genes. ${ }^{28}$ Among 22 countries in the Arab world totaling a population of 500 million, Saudi Arabia is one of the highest income countries in the Arabian Peninsula. In total, 955 genetic diseases have been acknowledged in the Arab population, ${ }^{29}$ whereas 7,500 disorders are documented in the global population. ${ }^{6}$ Bosdou et al. ${ }^{30}$ confirmed the connection between obesity and infertility in consanguineous women; an elevated BMI increases the risk of infertility due to hormonal abnormalities and ovulation dysfunction. However, genetic studies of the correlation between consanguinity and obesity are lacking. The lifestyle in Saudi Arabia has changed drastically since the discovery of oil and subsequent increases in wealth. Obesity in Saudi Arabia has become a serious health complication, resulting in preventable deaths, and is connected with an increase in chronic non-communicable diseases; $68 \%$ of citizens are classified as overweight or obese. ${ }^{31}$
The rs4646994 is one of the functional polymorphisms that appears on the ACE gene, which consists of the 287-bp Alu sequence. Heterozygosity (ID) in the Alu sequence may affect the $A C E$ gene expression and function of ACE-I, while the DD genotype is generally associated with limited health issues such as higher blood pressure. However, a strong relation was observed between HTN and obesity via the accumulation of additional adipose tissue, which initiates a cascade of events that lean towards elevated blood pressure. The $A C E \mathrm{DD}$ genotype raises the $A C E$ plasma concentration, and it does not reliably show a potential for various human diseases and the outcomes of case-control studies. The large impact and higher production of angiotensin II are correlated with the involvement of the $\mathrm{D}$ allele when compared with the II genotype and the I allele. Obesity-induced HTN is one of the most important pathways in infants, children, and adults. ${ }^{32-34}$ The study focused on the ACE gene to determine the effects of first-cousin consanguinity on offspring. ACE gene polymorphisms have been evaluated in all of the multifactorial inheritances of human diseases. The ACE enzyme has a connection with RAS and modulates the synthesis of angiotensin II and the inactivation of bradykinin. The $A C E$ ID polymorphism affects adipose tissue and is associated with HTN; diabetes nephropathy with angiotensin bradykinin is connected to coronary arteries and obesity. ${ }^{35} \mathrm{ACE}$ contributes substantially to T2DM as the RAS blockade improves insulin resistance. The major connection between obesity and ACE polymorphisms involves adipocyte growth and function and $A C E$ processing of angiotensin II, which inhibits adipocyte differentiation. The ACE ID polymorphism is also closely associated with susceptibility to metabolic disorders, which are related to central obesity. ${ }^{36}$ No studies have evaluated the offspring of first cousins with respect to obesity and $A C E$ gene polymorphisms. However, limited genetic studies of the global population have evaluated the association between obesity and ACE ID polymorphisms. ${ }^{37,38}$ El-Hazmi and Warsy ${ }^{39}$ examined the ACE ID polymorphism in obese Saudi patients and reported a positive effect of the DD genotype and D allele in overweight and obese subjects. Few studies of the Saudi population have evaluated $A C E$ gene polymorphisms with respect to multiple human diseases.

The heterozygous genotypes (ID) vary from our study (1.1\%) when compared with other obesity studies with non-consanguine- 
ous subjects. ${ }^{40}$ There is the possibility that offspring might receive the dominant alleles (deletion) from both parents because of consanguinity. However, from this single and low-sample-sized study, this is difficult to conclude. Apart from this, the control subjects in the present study, i.e., non-obese offspring in non-consanguineous parents, differed in the heterozygous genotypes (ID) of the $A C E$ gene when compared to the cases. However, the current study did not find any similar document for the genotype subjects with nonobese consanguineous first cousins in the Saudi population to compare the heterozygous allelic frequencies. The genotype frequencies observed in this study might vary with other study results due to the inclusion criteria of the study subjects and random control selection. This could also be one more reason for not matching the age and sex between the cases and controls.

Finally, some important limitations of this study need to be considered. Only one single nucleotide polymorphism was evaluated, which may be inadequate for assessing the risk levels associated with consanguinity. In addition, serum assays were not performed. Furthermore, these genotype data must be interpreted with caution because our population data were not consistent with those of other Saudi studies, and the sample size was not large enough. The final limitation of this study is that it was performed with the obese offspring of first cousins only, instead of also including non-obese offspring of non-consanguineous couples. Additional subject groups were not involved in this study.

In conclusion, this analysis of the ACE gene polymorphism showed a strong association between the allele frequencies in the offspring of consanguineous first cousins and obesity in the Saudi population. Future studies with larger sample sizes in a more globally diverse ethnic population are needed to confirm the results of our small case-control study in a different combination of selected subjects.

\section{CONFLICTS OF INTEREST}

The authors declare no conflict of interest.

\section{AUTHOR CONTRIBUTIONS}

Study concept and design, acquisition of data, analysis and interpretation of data, drafting of the manuscript, critical revision of the manuscript, statistical analysis, obtained funding, administrative, technical, or material support, and study supervision: all authors.

\section{SUPPLEMENTARY MATERIALS}

Supplementary Tables 1, 2 and Figures 1, 2 can be found via https://doi.org/10.7570/jomes20086.

\section{REFERENCES}

1. Hamamy H. Consanguineous marriages: preconception consultation in primary health care settings. J Community Genet 2012;3:185-92.

2. Abdalla B, Zaher A. Consanguineous marriages in the middle east: nature versus nurture. Open Complement Med J 2013; 5:1-10.

3. Ghrayeb FA. Consanguineous marriage and its effect on offspring congenital malformation: a study among Palestinian rural community. Int Med J 2016;23:355-7.

4. Fareed M, Afzal M. Evidence of inbreeding depression on height, weight, and body mass index: a population-based child cohort study. Am J Hum Biol 2014;26:784-95.

5. Sanyelbhaa H, Kabel A, El-Naga HA, Sanyelbhaa A, Salem H. The risk ratio for development of hereditary sensorineural hearing loss in consanguineous marriage offspring. Int J Pediatr Otorhinolaryngol 2017;101:7-10.

6. Erzurumluoglu AM, Shihab HA, Rodriguez S, Gaunt TR, Day IN. Importance of genetic studies in consanguineous populations for the characterization of novel human gene functions. Ann Hum Genet 2016;80:187-96.

7. Sadeghi S, Shevell M. Consideration of genetic diagnoses of developmental delay in children of consanguineous families. Semin Pediatr Neurol 2018;26:60-2.

8. Ajaz M, Ali N, Randhawa G. UK Pakistani views on the adverse health risks associated with consanguineous marriages. J Community Genet 2015;6:331-42.

9. Abdi Rad I, Bagheri M. Angiotensin-converting enzyme insertion/deletion gene polymorphism in general population of west Azarbaijan, Iran. Iran J Kidney Dis 2011;5:86-92.

10. Akin F, Turgut S, Bastemir M, Turgut G, Kursunluoglu R, 
Karasu U, et al. Angiotensin-converting enzyme gene polymorphism in overweight and obese Turkish patients with insulin resistance. DNA Cell Biol 2010;29:207-12.

11. Montague CT, Farooqi IS, Whitehead JP, Soos MA, Rau H, Wareham NJ, et al. Congenital leptin deficiency is associated with severe early-onset obesity in humans. Nature 1997;387: 903-8.

12. Tomei S, Mamtani R, Al Ali R, Elkum N, Abdulmalik M, Ismail A, et al. Obesity susceptibility loci in Qataris, a highly consanguineous Arabian population. J Transl Med 2015;13: 119.

13. Saeed S, Arslan M, Froguel P. Genetics of obesity in consanguineous populations: toward precision medicine and the discovery of novel obesity genes. Obesity (Silver Spring) 2018; 26:474-84.

14. Bordoni L, Marchegiani F, Piangerelli M, Napolioni V, Gabbianelli R. Obesity-related genetic polymorphisms and adiposity indices in a young Italian population. IUBMB Life 2017; 69:98-105.

15. Al-Ghamdi S, Shubair MM, Aldiab A, Al-Zahrani JM, Aldossari KK, Househ M, et al. Prevalence of overweight and obesity based on the body mass index: a cross-sectional study in Alkharj, Saudi Arabia. Lipids Health Dis 2018;17:134.

16. Kasim NB, Huri HZ, Vethakkan SR, Ibrahim L, Abdullah BM. Genetic polymorphisms associated with overweight and obesity in uncontrolled type 2 diabetes mellitus. Biomark Med 2016;10:403-15.

17. Engeli S, Negrel R, Sharma AM. Physiology and pathophysiology of the adipose tissue renin-angiotensin system. Hypertension 2000;35:1270-7.

18. Rigat B, Hubert C, Alhenc-Gelas F, Cambien F, Corvol P, Soubrier F. An insertion/deletion polymorphism in the angiotensin I-converting enzyme gene accounting for half the variance of serum enzyme levels. J Clin Invest 1990;86:1343-6.

19. Abouelfath R, Habbal R, Laaraj A, Khay K, Harraka M, Nadifi S. ACE insertion/deletion polymorphism is positively associated with resistant hypertension in Morocco. Gene 2018;658: 178-83.

20. Khan IA, Jahan P, Hasan Q, Rao P. Angiotensin-converting enzyme gene insertion/deletion polymorphism studies in
Asian Indian pregnant women biochemically identifies gestational diabetes mellitus. J Renin Angiotensin Aldosterone Syst 2014;15:566-71.

21. Sahoo K, Sahoo B, Choudhury AK, Sofi NY, Kumar R, Bhadoria AS. Childhood obesity: causes and consequences. J Family Med Prim Care 2015;4:187-92.

22. Magbool GM. Body mass index of Saudi children ages six to 16 years from the eastern province. Ann Saudi Med 1994;14: 495-8.

23. Memish ZA, El Bcheraoui C, Tuffaha M, Robinson M, Daoud F, Jaber S, et al. Obesity and associated factors: Kingdom of Saudi Arabia, 2013. Prev Chronic Dis 2014;11:140236.

24. Al-Shehri FS, Moqbel MM, Al-Khaldi YM, Al-Shahrani AM. Prevention and management of obesity: Saudi guideline update. Saudi J Obes 2016;4:25.

25. Alfares A, Alfadhel M, Wani T, Alsahli S, Alluhaydan I, Al Mutairi F, et al. A multicenter clinical exome study in unselected cohorts from a consanguineous population of Saudi Arabia demonstrated a high diagnostic yield. Mol Genet Metab 2017;121:91-5.

26. Hamamy HA, Masri AT, Al-Hadidy AM, Ajlouni KM. Consanguinity and genetic disorders: profile from Jordan. Saudi Med J 2007;28:1015-7.

27. Shawky RM, Elsayed SM, Zaki ME, Nour El-Din SM, Kamal FM. Consanguinity and its relevance to clinical genetics. Egypt J Med Hum Genet 2013;14:157-64.

28. MacArthur DG, Balasubramanian S, Frankish A, Huang N, Morris J, Walter K, et al. A systematic survey of loss-of-function variants in human protein-coding genes. Science 2012; 335:823-8.

29. Zayed H. The Arab genome: health and wealth. Gene 2016; 592:239-43.

30. Bosdou JK, Kolibianakis EM, Tarlatzis BC, Fatemi HM. Sociocultural influences on fertility in the Middle East: the role of parental consanguinity, obesity and vitamin $\mathrm{D}$ deficiency. Fertil Steril 2016;106:259-60.

31. Alharbi KK, Syed R, Alharbi FK, Khan IA. Association of apolipoprotein E polymorphism with impact on overweight university pupils. Genet Test Mol Biomarkers 2017;21:53-7.

32. Zmorzynski S, Szudy-Szczyrek A, Popek-Marciniec S, Korszen- 
Pilecka I, Wojcierowska-Litwin M, Luterek M, et al. ACE insertion/deletion polymorphism (rs4646994) is associated with the increased risk of multiple myeloma. Front Oncol 2019;9:44.

33. Leggio M, Lombardi M, Caldarone E, Severi P, D’Emidio S, Armeni M, et al. The relationship between obesity and hypertension: an updated comprehensive overview on vicious twins. Hypertens Res 2017;40:947-63.

34. Higaki J, Baba S, Katsuya T, Sato N, Ishikawa K, Mannami T, et al. Deletion allele of angiotensin-converting enzyme gene increases risk of essential hypertension in Japanese men: the Suita Study. Circulation 2000;101:2060-5.

35. Feher A, Cassuto J, Szabo A, Patel V, Vinayak Kamath M, Bagi $Z$. Increased tissue angiotensin-converting enzyme activity impairs bradykinin-induced dilation of coronary arterioles in obesity. Circ J 2013;77:1867-76.

36. Mao Y, Xu X, Wang X, Zheng X, Xie L. Is angiotensin-converting enzyme inhibitors/angiotensin receptor blockers ther- apy protective against prostate cancer? Oncotarget 2016;7: 6765-73.

37. Motawi TK, Shaker OG, Shahin NN, Ahmed NM. Angiotensin-converting enzyme insertion/deletion polymorphism association with obesity and some related disorders in Egyptian females: a case-control observational study. Nutr Metab 2016;13:68.

38. Pan YH, Wang M, Huang YM, Wang YH, Chen YL, Geng LJ, et al. ACE gene I/D polymorphism and obesity in 1,574 patients with type 2 diabetes mellitus. Dis Markers 2016;2016: 7420540.

39. El-Hazmi MA, Warsy AS. Increased frequency of angiotensinconverting enzyme DD genotype in Saudi overweight and obese patients. Ann Saudi Med 2003;23:24-7.

40. Alharbi SA. Angiotensin I converting enzyme gene polymorphism in type 2 diabetes mellitus with nephropathy in Saudi population. Int J Med Res Health Sci 2017;6:12-20. 